\title{
Research on the Application Effects of Orff's Music Teaching Idea in Music Education in Colleges and Universities
}

\author{
Dandan Dai \\ Nanchang Vocational College, Nanchang, 330000
}

Keywords: Orff's music teaching idea, music education in colleges and universities, application effect, development direction

\begin{abstract}
Orff's music teaching idea is a very important teaching method, which emphasizes the coordination of various ways and methods, such as music, language and action and mutually complementary music learning method based on the original music theory. To apply Orff's music idea for efficient music education allows students to better participate in music and feel music, based on which, it is conducive to improving the ability of students to create music. So far the application has achieved good results and has effectively improved the quality of music teaching. In this premise, music educators should deepen the research and exploration of Orff's music teaching idea combining with the teaching characteristics of colleges and universities and excavate contents of Orff's music teaching idea which are more suitable to apply in teaching. This paper will analyze the application effects of Orff's music teaching idea in music teaching, and explain its development direction.
\end{abstract}

\section{Introduction}

With the progress of our society, the quality of people's material life has been greatly improved, and the demand for spiritual field is also increasing. How to improve the quality of spiritual level is one of the key goals of music teaching in colleges and universities. As an important form of artistic expression, music can improve the comprehensive quality of students and cultivate their artistic feeling and personal temperament. Improving the quality of music teaching in colleges and universities is in favor of putting a positive impact on students' ability to appreciate art and express music, enhancing their overall competitive ability for entering the society in the future, and promoting them to become comprehensive and high-quality talents who are urgently needed by current society. However, teaching centers of a large part of colleges and universities still concentrate on professional teaching, neglecting the cultivation of the comprehensive quality of students, which will have adverse effects on the overall quality of teaching and the development of education. Therefore, colleges and universities should improve teaching methods of music, apply innovative teaching styles in teaching, and enhance the quality of music teaching.

\section{A Brief Analysis of Orff's Music Teaching Idea}

Orff's music teaching idea is a kind of music teaching method founded by German music educationist, Karl Orff. This teaching method has a strong comprehensiveness characteristic and attaches great importance to the performance of the original character of music. That is to say, if we want to get better teaching results through this teaching idea, it is necessary to create and explore the traditional teaching method, let students experience and understand music by themselves, as well as get spiritual resonance through personal perception, thus improving students' learning ability of music. The application of this music teaching idea to carry out actual teaching of music is propitious to better reflect people-oriented idea, and meet teaching requirements of our country. This general teaching idea requires students to combine their own basic musical ability, and subjectively experience, feel and understand music. It also has multiple functions in music teaching, such as creating music games, organizing physical activities, dancing and so on. Through musical elements such as language and rhythm, music is better displayed and expressed. These teaching 
methods can enrich students' actual experience of music in class and promote the realization of teaching goals. Besides, this teaching method has great adaptability, so when applying it to music teaching, colleges and universities should pay attention to its application status and effects. Under normal circumstances, this teaching idea will achieve better teaching results, in favor of offering guidance to some students with poor music foundation, obviously improving their musical quality and ability, better reflecting the diversity of teaching, and improving students' music skills and comprehensive quality. Based on the above analysis, educators should realize that Orff's music teaching idea is not only a simple innovative teaching method, but also a change in educational concept. By learning and creating music in a pluralistic way, students are able to have a deeper experience of music under the reasonable guidance of teachers.

\section{Analysis of the Application Effects of Orff's Music Teaching Idea in Music Teaching in Colleges and Universities}

The learning of music course has a certain connection with other courses, as well as students' life habits. When students have just entered the campus, they will feel strange to the new way of life, feel uncomfortable to communicate with other students, behave without confidence to a certain degree in life and learning and care too much to get others' affirmation. Teaching spirit of respecting others in Orff's music teaching idea can promote students to establish healthy communication modes and enhance their concern for others. College students are in puberty with obvious psychological characteristics of teenagers. In learning, they pay more attention to the pursuit of self, so a reasonable teaching methods should focus on students, understand their psychological demands at this stage, so as to better integrate into their hearts and improve the effectiveness of teaching. In order to better improve the quality of music teaching, teachers are required to provide some music materials for students by rational use of the teaching method of music games, let students learn music in games, improve their interest in music art, and stimulate their enthusiasm to learn. Orff's music teaching idea is propitious to better stimulate students' brain activity, think deeply about music, and improve their own music quality in a relaxed environment atmosphere.

Different from the traditional music teaching mode, Orff's music teaching idea stresses students' participation in the classroom music learning, and changes the single passive way of learning into an interactive way. In the course of teaching, students no longer just rely on the method of appreciation, but participate in music creation and other activities under teachers' guidance, such as musical instrument playing. Orff's teaching method is good at using daily instruments, especially some rhythmic instruments, such as drums and other percussion instruments, because this kind of musical instruments is relatively simple and does not require students to have a very strong musical basis. Low requirement effectively improves students' confidence in learning music and makes it easy for beginners to play the instrument and participate in music classroom. In the process of music teaching, teachers should play a positive role in guiding students to create practical conditions. For example, through the use of simple instruments, teachers enable students to create music based on their feelings and music accumulation, release their own nature, excavate musical competence, and get the maximum release. Through the continuous improvement of students' musical ability, it is propitious to make them understand the importance of music practice better, improve students' active participation, better cooperate with teachers' various teaching activities, so as to help students get better learning ability.

Whether teaching objectives can be achieved or whether teaching activities can be carried out smoothly relies on the correctness of teaching ideas to a large extent. Only with an objective and reasonable evaluation of teaching ideas, can teachers better know teaching and learning effects. In traditional teaching methods, the assessment of students is the only way to know teaching quality and effects. Similarly, music course takes this method to test students' ability in a long time. In this way, students' learning purpose is more changed into how to get better test results, which leads to the deviation of students' learning methods and limits their mastery of music. Orff's music teaching idea does not advocate the judgment of students' musical ability through a test, but a comprehensive and flexible evaluation by connecting music teaching system. That means, it will evaluate the 
meaning of teaching idea, as well as the effects of teaching curriculum and teaching methods of music. This kind of evaluation method can be used in any stage of teaching process, through which, teachers are able to evaluate students by taking daily observation into consideration and improve the integrity and comprehensiveness of students' evaluation.

\section{Innovation and Development of Orff's Music Teaching Idea in Colleges and Universities}

In the specific teaching process of music, it is feasible to combine Orff's music teaching idea to enable students to create performance and improvisation in class. Improvisational performance is the core part of this music teaching idea, through which, students are able to develop their creative ability and teachers can also discover students' musical potential by observing their ability to improvise. After entering colleges and universities, once students have entered the learning state, teachers begin to apply this teaching method to improve students' interest in learning. Firstly, teachers are capable of optimizing students' thinking mode by through questions and discussions. Then, students are encouraged to participate in music games of role playing. In the games, they can freely display their imagination and create music. In addition, students are able to create creative performances by combining sounds, movements and musical instruments and then discover various possibilities in music. During this process, not only new types of music can be created, but also students' own way of learning or even their own notation will be formed under teachers' proper guidance. Orff once said that in the process of learning music, only by making students more active in the creation of music can get better teaching results. When students interpret music in a way of improvisation, they can be of the same value as a master of music. In the creation of music, students need teachers' encouragement and affirmation, then students will be more willing to use music to express their feelings, to give ideas to music, and to use music to communicate and express emotions.

When Orff's music teaching idea is applied in the music teaching of various countries, differences of culture and national condition have made a certain improvement to adapt to the music teaching system of the country. Based on the cultural characteristics of our country and in the application of Orff's music teaching concept, it is possible to find available resources from the local culture of our country. While developing music education, it can also carry forward our traditional culture better, so that the music teaching of our country will be with more distinctive features. Orff's music teaching idea emphasizes that in the process of music teaching, teachers should actively integrate music with national characteristics to carry out specific teaching. However, in this respect, the educational level of national music in Chinese music teaching is not high. Especially some young people at present lack understanding of the traditional music culture and musical instruments in our country, most of whom do not have related basis and feel difficult to accept the traditional musical style. In order to let Orff's music teaching idea play a role better in music teaching in China's colleges and universities, it is suggested to improve the comprehensive quality of the whole people by setting up the curriculum of national music teaching. In teaching, teachers are advised to pay attention to knowledge popularization of traditional music and national musical instruments, provide students with traditional music materials, let students appreciate traditional music in class, analyze profound connotation of traditional music deeply, and improve students' ability to appreciate this style of music. It is also suggested to enable students to contact and learn national musical instruments in combination with traditional music, so as to improve teaching quality.

\section{Conclusion}

The application of Orff's music teaching idea to music teaching in colleges and universities can not only effectively change the way of music teaching, but also innovate the idea of music teaching, which is an effective way to promote music teaching reform. To use Orff's music teaching theory to guide music teaching is the result of continuous summary in practice, and the feasibility has been recognized by more and more people. Music educators should deepen the exploration and research 
in this field, improve the teaching quality of music courses in colleges and universities, and cultivate more talents with comprehensive quality for our country.

\section{Acknowledgement}

The work was supported by the Topic of Nanchang Vocational College with the project number 2016-026 and the project name Research on the Reform and Practice of Music Curriculum System in Higher Vocational Colleges Based on the Promotion of Employability.

\section{References}

[1] Li Yexue. Application Value of Orff's Music Education System in Public Music Education in Colleges and Universities [D]. Capital Normal University, 2006.

[2] Lin Lin. On the Practical Significance of “Orff” Teaching Method in Music Education in Colleges and Universities [J]. Drama Home, 2015,17:187+189.

[3] Yu Minhui. Application of Orff's Music Teaching System in Piano Collective Teaching in Colleges and Universities [J]. Mass Literature and Art, 2013,07:123-124.

[4] Zhao Yunjie. Application Value of Orff's Music Education System in Public Music Education in Colleges and Universities. [J]. Art Evaluation, 2017,03:129-131.

[5] Yi Ling. Application of Orff's Music Education Method in Music Teaching in Colleges and Universities [J]. Shaanxi Education (Higher Education), 2017,06:17-18.

[6] He Lu. Localization Practice of Orff's Teaching Idea [D]. Xinghai Conservatory of Music, 2009. 